\title{
Parvovirus B19 is associated with benign testes as well as testicular germ cell tumours
}

\author{
T C Diss, L X Pan, M Q Du, H Z Peng, J R Kerr
}

\begin{abstract}
Aims-Parvovirus B19 has been demonstrated in testes of patients with germ cell tumours but not in controls, raising the possibility that the virus has an aetiological role in these tumours. The aims of this study were to investigate the association of the virus with germ cell tumours and to localise the virus histologically.

Methods-DNA was extracted from paraffin wax embedded sections of testes from 10 seminomas, eight teratomas, two mixed seminoma/teratomas, and 10 testes showing benign histology. Polymerase chain reaction (PCR) amplification of three regions within the NS and VP1/2 genes was carried out in duplicate on all samples. One PCR positive case (seminomal teratoma) was examined by microdissection of histologically defined tissue components followed by PCR amplification of parvoviral sequences. Samples from PCR positive patients were immunostained using a B19 specific monoclonal antibody.
\end{abstract}

Results-Seven cases were PCR positive, these comprised two of 10 seminomas, one of two mixed tumours, none of eight teratomas, and four of 10 benign controls. PCR analysis of the material microdissected from the seminoma/teratoma showed the presence of the virus in regions of seminoma, teratoma, intratubular germ cell neoplasia, normal tubules, and connective tissue. All patient samples studied immunohistochemically were negative.

Conclusions-This confirms the presence of parvovirus B19 in a proportion of germ cell tumours; however, in one patient, the virus was widespread in the tissue components and not confined to tumour cells. In addition, the virus was present in control benign testes. These data suggest that B19 might not be of aetiological importance in germ cell tumours of testis.

(F Clin Pathol: Mol Pathol 1999;52:349-352)

Keywords: parvovirus B19; testicular germ cell tumours; tumour aetiology

Department of Virology, Royal Free and University College London Medical

School

J R Kerr

Correspondence to: Dr Diss

email: t.diss@ucl.ac.uk

Accepted for publication 24 August 1999 includes both lytic infection of red blood cell progenitors and immune complex deposition. A recent study has implicated B19 in human cancer for the first time. ${ }^{3}$ The virus was detected by polymerase chain reaction (PCR) in testes of patients with germ cell tumours but not in benign controls. This suggests that B19 might have an aetiological role in these tumours. However, it was not shown whether the virus was localised in tumour cells or in normal cells present in the tissue samples. The aims of our study were to confirm the association of the virus with germ cell tumours and to localise the virus histologically.

\section{Methods}

\section{PATIENT SAMPLES}

Paraffin wax blocks were obtained from the archives of the histopathology department at University College Medical School, London, UK. Blocks of testicular tissue were selected from 10 patients with seminomas (average age, 39 years), two with mixed germ cell tumours (seminoma/teratoma; average age, 42 years), eight with teratomas (average age, 31 years) and a control group of 10 showing benign histology (nine from patients with carcinoma of prostate; average age, 70 ; one with undescended testis removed at 88 years). Sections ( $5 \mu \mathrm{m}$ thick) were cut from each block and placed into $0.5 \mathrm{ml}$ microtubes for DNA extraction. Different regions of new microtome blades were used for each block to minimise the risk of cross contamination. Sample handling, DNA extraction, and PCR analysis were performed in laboratories that were separate from those where B19 diagnostics are carried out.

POLYMERASE CHAIN REACTION

DNA was extracted by overnight treatment at $37^{\circ} \mathrm{C}$ with $100-200 \mu \mathrm{l}$ of proteinase $\mathrm{K}(200 \mu \mathrm{g} /$ $\mathrm{ml}$; Sigma, Poole, Dorset, UK) in PCR buffer (Promega, Southampton, UK), followed by heat inactivation of the enzyme. ${ }^{4}$ Three PCR protocols were used for the detection of parvovirus B19, targeting different regions of the viral genome (fig 1). Two $5 \mu \mathrm{l}$ aliquots of each sample were amplified using primers directed to the parvovirus VP1/2 gene (primer sets VP1/2a (product size, $103 \mathrm{bp}$ ) and VP1/2b (product size, $111 \mathrm{bp}$ )) and to the NS gene (product size, $103 \mathrm{bp}$ ). Primers were designed or adapted from published sequences ${ }^{3}$ to yield small fragments in an attempt to achieve efficient amplification from potentially highly degraded DNA samples extracted from paraffin wax embedded samples. DNA extracted from a paraffin wax block of fetal lung, which had been shown to harbour B19 by means of in situ hybridisation was used as a positive control, and a reaction mixture without template DNA was used as a negative control 


NS (436-2451) $\quad$ VP1/2 (2444-4766)
\begin{tabular}{|l|l|}
\hline NS (1498-1600) & \\
\hline VP1/2b (3117-3227) \\
VP1/2a (3187-3290)
\end{tabular}

Figure 1 Parvovirus B19 genome showing the NS and VP1/2 coding regions and approximate primer locations. Nucleotide numbers are shown in parentheses. Primer sequences were as follows: VP1/2a, CAAAAGCATGTG GAGTGAGG and CCTTATAATGGTGCTCTGGG (newly designed), product size $103 \mathrm{bp}$; VP1/2b, ACCCA $A G C A T G A C T T C A G T T^{3}$ and AGTTGGCACTAA AAGTGGCC (newly designed), product size $111 \mathrm{bp}$; NS, AATGAAAACTTTCCATTTAAT GATGTAG and CTAAAAATGGCTTTTGCAGCTTCTAC, ${ }^{5}$ product size $103 \mathrm{bp}$.

in all experiments. Reaction mixtures contained $10 \mathrm{mM}$ Tris/ $\mathrm{HCl}$ (pH 9.0), $50 \mathrm{mM}$ $\mathrm{KCl}, 1.5 \mathrm{mM} \mathrm{MgCl}_{2}, 200 \mu \mathrm{M}$ each dNTP, 250 ng each primer, $0.1 \%$ Triton $\mathrm{X}-100$, and $0.5 \mathrm{U}$ of Taq polymerase (Promega) in a total volume of $50 \mu \mathrm{l}$. After "hot start", 40 cycles of PCR were carried out as follows: 40 seconds at $93^{\circ} \mathrm{C}, 45$ seconds at $55^{\circ} \mathrm{C}\left(61^{\circ} \mathrm{C}\right.$ for $\mathrm{VP} 1 / 2 \mathrm{a}$ primers), and 110 seconds at $72^{\circ} \mathrm{C}$. Products were analysed in a separate laboratory to the one used to set up the PCR, using 10\% polyacrylamide minigels that were stained with ethidium bromide and viewed under UV light. Samples that yielded products of the expected size in duplicate reactions were recorded as positive. Results were interpreted without knowledge of the diagnoses. All DNA extracts were tested for the presence of suitable DNA by amplification of a $250 \mathrm{bp}$ fragment of the $\beta$-globin gene. ${ }^{5}$

\section{MICRODISSECTION}

Selected areas from haematoxylin and eosin stained sections from patient 11 were microdissected manually with drawn out glass pipettes using the method described by Pan et al. ${ }^{6}$ Areas of seminoma, teratoma, and intratubular germ cell neoplasia were selected, as well as areas of normal tubules and connective tissue distant from tumour foci (fig 2). Clean pipettes were used for each microdissected area to minimise cross contamination. Aliquots of ethanol solutions used to contain sections before and after microdissection were used as additional negative controls. DNA was extracted as described above, but using $25 \mu \mathrm{l}$ of proteinase $\mathrm{K}$ buffer and an extended digestion step of three days. Duplicate $5 \mu \mathrm{l}$ aliquots were analysed by PCR amplification of the parvovirus genome using $\mathrm{VP} 1 / 2 \mathrm{~b}$ primers. In addition, DNA was extracted from all available tissue blocks from
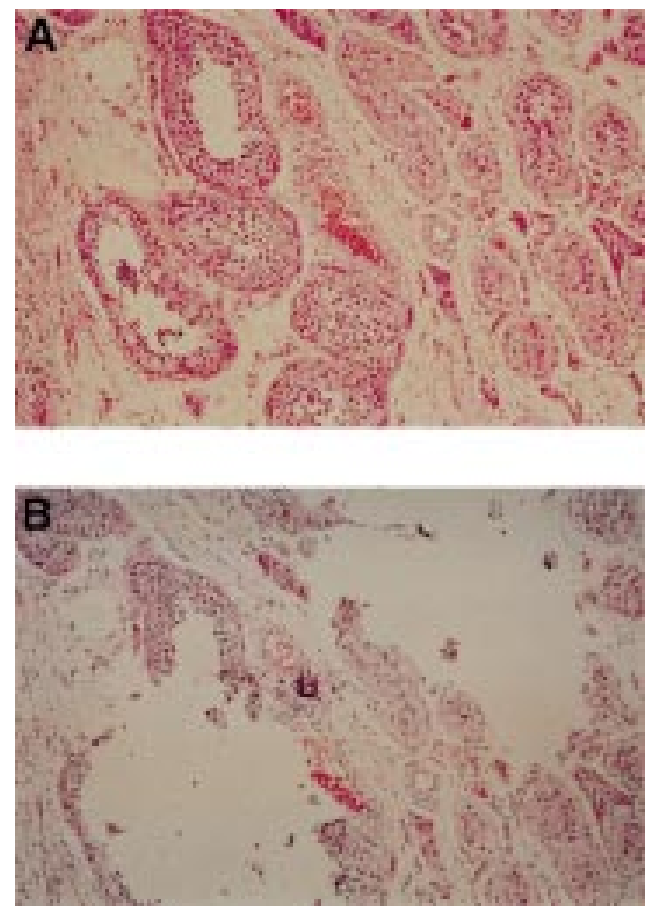

Figure 2 (A) Areas of normal tubules (left) and intratubular germ cell neoplasia (right) from patient 11 before microdissection. (B) Same areas after microdissection of each component separately. Haematoxylin and eosin stained.

patient 11 and analysed using VP1/2b primers (table 1). Microdissection of seminoma and normal components from patients 1 and 6 was also carried out, and extracts subjected to PCR using $\mathrm{VP} 1 / 2 \mathrm{~b}$ primers.

SINGLE STRAND CONFORMATIONAL

POLYMORPHISM (SSCP)

VP1/2b PCR products derived from six testicular samples were analysed by SSCP using the Genephor apparatus (Pharmacia, St Albans, UK). Denatured products were run on precast $12 \%$ gels at $8 \mathrm{~W}$ for two and a half hours and automatically silver stained under the conditions recommended by the manufacturer.

\section{IMMUNOHISTOCHEMISTRY}

Immunohistochemistry was performed on the seven PCR positive cases (patients 1, 6, 11, 26, 28,29 , and 30) using a streptavidin-biotin peroxidase method with an antibody directed to the B19 VP1 and VP2 capsid proteins (Novacastra, Newcastle upon Tyne, UK). ${ }^{7}$

Table 1 Microdissection and polymerase chain reaction (PCR) analysis of samples from patient 11

\begin{tabular}{cll}
\hline & Site & Cellular composition \\
\hline Block & Right testis, tumour & Right testis, whole section. Seminoma, teratoma, ITGCN, normal tubules \\
1 & MD-A & Seminoma \\
1 & MD-B & Teratoma \\
1 & MD-C & Intratubular germ cell neoplasia \\
1 & MD-D & Normal tubules \\
1 & MD-E & Connective tissue \\
1 & Washings from microdissection experiments & No tissue \\
Control & Left testis & Normal spermatogenesis. No tumour \\
2 & Right testis, cord margin & Cord, vas deferens. No tumour \\
3 & Right testis, lower cord & Cord, vas deferens. No tumour \\
4 & Right testis, tumour & Teratoma, ITGCN, normal tubules \\
5 & Right testis, distant from tumour mass & Teratoma, ITGCN, normal tubules \\
6 & + & + \\
\hline
\end{tabular}

ITGCN, intratubular germ cell neoplasia; $\mathrm{MD}$, microdissected area. 


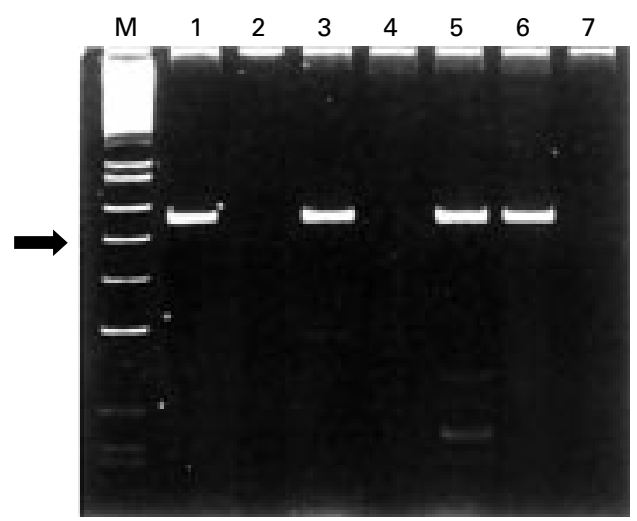

Figure 3 Polyacrylamide gel of VP1/2b PCR products. Lane $M, \phi X$-Hinfl molecular weight markers (the $100 \mathrm{bp}$ fragment is indicated by an arrow); lane 1, positive control showing 111 bp fragment; lane 2, negative control; lane 3, patient 26; lane 4, patient 27; lane 5, patient 28; lane 6, patient 29; lane 7, patient 30.

\section{Results}

POLYMERASE CHAIN REACTION

Seven of the 30 patients analysed were positive. Three benign controls and one mixed seminoma/teratoma were positive with all three sets of primers. Two seminomas were positive with the NS and VP1/2b sets and a single benign control was positive with the NS primers alone (fig 3; table 2). Three patients yielded PCR products with a single primer set in one of two initial duplicate reactions. Two further repeats were negative in each patient, and these samples were recorded as negative to exclude sporadic false positives. Positive and negative controls gave the appropriate results in each experiment. $\beta$-Globin PCR confirmed the

Table 2 Patient samples and results of polymerase chain reaction (PCR) and immunohistochemical (ICH) analyses

\begin{tabular}{|c|c|c|c|c|c|c|}
\hline Patient & $\begin{array}{l}\text { Age } \\
\text { (years) }\end{array}$ & Diagnosis & $\begin{array}{l}P C R- \\
V P 1 / 2 A\end{array}$ & $\begin{array}{l}P C R- \\
V P 1 / 2 B\end{array}$ & PCR-NS & $I H C$ \\
\hline 1 & 54 & SEM & - & + & + & - \\
\hline 2 & 43 & SEM & - & - & - & ND \\
\hline 3 & 41 & SEM & - & - & - & ND \\
\hline 4 & 39 & SEM & - & - & - & ND \\
\hline 5 & 38 & SEM & - & - & - & ND \\
\hline 6 & 35 & SEM & - & + & + & - \\
\hline 7 & 33 & SEM & - & - & - & ND \\
\hline 8 & 33 & SEM & - & - & - & ND \\
\hline 9 & 29 & SEM & - & - & - & ND \\
\hline 10 & 45 & SEM & - & - & - & ND \\
\hline 11 & 30 & $S+T$ & + & + & + & - \\
\hline 12 & 25 & $\mathrm{~S}+\mathrm{T}$ & - & - & - & ND \\
\hline 13 & 35 & TER & - & - & - & ND \\
\hline 14 & 30 & TER & - & - & - & ND \\
\hline 15 & 26 & TER & - & - & - & ND \\
\hline 16 & 29 & TER & - & - & - & ND \\
\hline 17 & 26 & TER & - & - & - & ND \\
\hline 18 & 20 & TER & - & - & - & ND \\
\hline 19 & 51 & TER & - & - & - & ND \\
\hline 20 & 31 & TER & - & - & - & ND \\
\hline 21 & 80 & CA-P & - & - & - & ND \\
\hline 22 & 74 & CA-P & - & - & - & ND \\
\hline 23 & 70 & CA-P & - & - & - & ND \\
\hline 24 & 69 & CA-P & - & - & - & ND \\
\hline 25 & 76 & CA-P & - & - & - & ND \\
\hline 26 & 77 & CA-P & + & + & + & - \\
\hline 27 & 72 & CA-P & - & - & - & ND \\
\hline 28 & 62 & CA-P & + & + & + & - \\
\hline 29 & 47 & CA-P & + & + & + & - \\
\hline 30 & 88 & UND & - & - & + & - \\
\hline Total & & & $4 / 30$ & $6 / 30$ & $7 / 30$ & $0 / 7$ \\
\hline
\end{tabular}

SEM, seminoma; $\mathrm{S}+\mathrm{T}$, seminoma/teratoma; TER, teratoma; CA-P, uninvolved testis from patient with carcinoma of the prostate; UND, undescended testes; ND, not done.

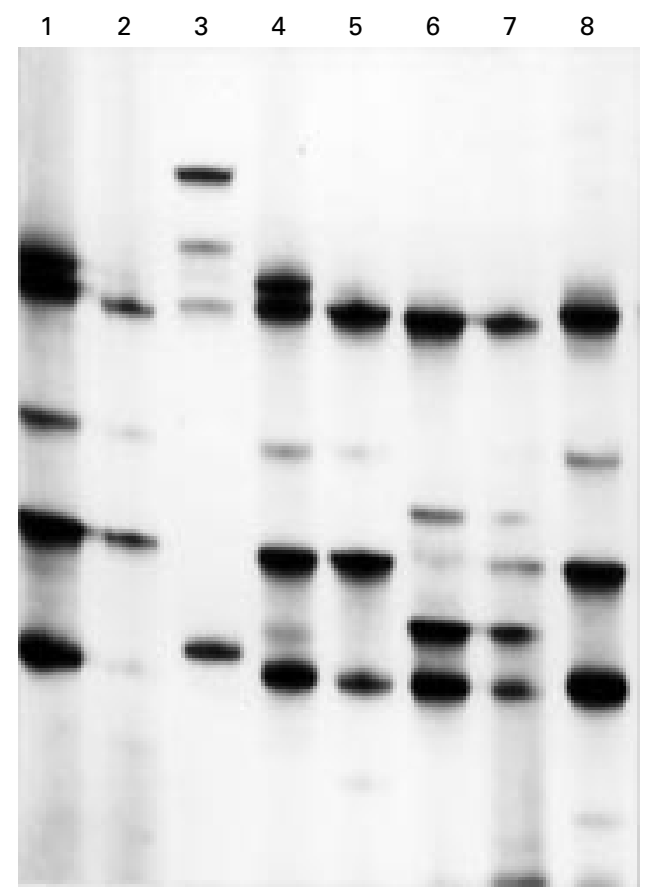

Figure 4 Single strand conformational polymorphism gel showing VP1/2b PCR products from six different patients (two different products from patients 1 and 26 have been run). Lane 1, patient 1; lane 2, patient 26; lane 3, patient 6; lane 4, patient 1; lane 5, patient 26; lane 6, patient 28; lane 7 , patient 29; lane 8 , patient 11 .

presence of amplifiable DNA in all extracts from complete sections.

\section{MICRODISSECTION}

B19 PCR products of the expected size were amplified from all microdissected tissue components (seminoma, teratoma, intratubular germ cell neoplasia, normal tubules, and connective tissue) from patient 11 (table 1). The same results were seen from at least two separate microdissections and PCR amplifications of each component. All tissue blocks from this patient were also shown to contain B19 viral DNA (table 1). $\beta$-Globin PCR products were amplified from all DNA samples from patient 11. No parvovirus PCR products were amplified from microdissected areas from patients 1 and 6 , and $\beta$-globin products were amplified from less than $50 \%$ of the samples from these patients, suggesting that insufficient suitable DNA had been extracted.

SINGLE STRAND CONFORMATIONAL

POLYMORPHISM

VP1/2b PCR products from six patients showed four different patterns on the SSCP gel (fig 4). These patterns were reproducible on repeated analysis and all results from a given patient were consistent.

IMMUNOHISTOCHEMISTRY

No positive signal was seen in any sample studied, although the B19 control gave the expected pattern of staining.

\section{Discussion}

Gray et al report the presence of B19 DNA in 33 of 39 frozen tissue samples from patients with testicular germ cell tumours. ${ }^{3}$ In our 
study, we were able to confirm the presence of the virus in germ cell tumours, although in only three of 20 patients. The previous study reported no B19 DNA in 12 benign controls, whereas we found evidence of the virus in four of our 10 benign samples.

Microdissection of histologically defined tissue components in a single germ cell tumour suggested that the virus was widespread throughout the section, including benign tissue as well as areas of seminoma and teratoma. It is possible that rare B19 positive tumour cells contaminated our microdissected benign tissue samples, although whole sections of cord and vas deferens and a left testicular biopsy showing no evidence of tumour cells were also positive. At present we can only speculate as to which cells carry the virus, because our attempts to localise the virus using in situ hybridisation have not been successful to date, probably because of low viral copy numbers (not shown). We cannot definitely rule out cross contamination of microdissected samples with B19 DNA, although this is unlikely in view of the reproducibility of our results and the precautions taken.

The reasons for our much lower detection rates in tumour samples could be related to our use of paraffin wax embedded samples as opposed to frozen tissue samples, or to the use of different primers. Paraffin wax embedded samples yield relatively degraded DNA, which might have resulted in a lower sensitivity in our study. However, our design of primers that amplified short fragments, the use of primers that targeted multiple sites, the positivity of extracts using control primers, and our increased detection rate in benign testes argue against this. Nevertheless, it is possible that samples with low cellular viral infection rates and low copy number were falsely negative using paraffin wax embedded tissue samples. Our increased detection rate in benign controls might be related to the age of the patients studied or to the selection of cases, although the total numbers studied to date are low. The incidence of parvovirus infection might also have been underestimated as a result of variability of the B19 genome, which is known to occur during persistent infection. ${ }^{8}$ SSCP analysis of B19 PCR products confirmed variability ${ }^{389}$ within the viral genome and suggested that our positive signals were not the result of cross contamination of samples. The use of multiple primers for parvovirus detection is therefore necessary, although four of our seven positive cases were amplified with all three sets of primers.
Our results indicate that B19 DNA might be present in non-tumour cells in orchidectomies performed for the treatment of germ cell tumours, and that the virus is present in benign testes. Therefore, the virus might be a passenger in germ cell tumours. Whether infection of germ cells by B19 occurs, and whether it confers an increased risk of germ cell tumours, and at what stage infection occurs, remain to be elucidated. Lack of expression of viral capsid genes in our patients supports the hypothesis that the virus is inactive. The means of B19 persistence is unclear at present. B19 DNA has also been detected in the synovium of patients with osteoarthritis and rheumatoid arthritis in the absence of expression of the gene encoding the B19 capsid protein. ${ }^{10}$ The cell type that harbours the virus and the mechanism of persistence in these conditions are unknown.

In conclusion, we have confirmed the presence of parvovirus B19 in a proportion of patients with testicular germ cell tumours and shown that benign testes might also be infected. Our findings suggest that the virus, even if present in tumours, is not restricted to tumour cells, and they indicate that the virus might not be involved directly in the evolution of germ cell tumours. Further work is required to understand the site of viral incorporation, the importance of that event, and to determine the range of cells and tissues in which it is located.

We are grateful to Dr MC Parkinson for selecting appropriate areas of tissue sections for microdissection, for photography, and for critical reading of the manuscript.

1 Cossart YE, Field AM, Cant B, et al. Parvovirus-like particles in human sera. Lancet 1975;I:72-3.

2 Kerr JR. Parvovirus B19 infection. Eur f Clin Microbiol Infect Dis 1996;15:10-29.

3 Gray A, Guillou L, Zuffery J, et al. Persistence of parvovirus B19 DNA in testis of patients with testicular germ cell tumors. F Gen Virol 1998;79:573-9.

4 Diss TC, Pan L, Peng H, et al. Sources of DNA for detecting B cell monoclonality using PCR. F Clin Pathol 1994;47: 493-6.

5 Saiki RK, Scharf S, Faloona F, et al. Enzymatic amplification of the $\beta$-globin genomic sequences and restriction site analysis for diagnosis of sickle cell anaemia. Science 1985;230:1350-4

6 Pan LX, Diss TC, Peng HZ, et al. Clonality analysis of defined B-cell populations in archival tissue sections using microdissection and the polymerase chain reaction. Histopathology 1994;24:323-7.

7 Morey AL, O'Neill HJ, Coyle PV, et al. Immunohistological detection of human parvovirus B19 in formalin-fixed, paraffin-embedded tissues. F Pathol 1992;166:105-8.

8 Kerr JR, Curran MD, Moore JE, et al. Persistent parvovirus B19 infection. Lancet 1995;345:1118.

9 Durigon EL, Erdman DD, Gary GW, et al. Multiple primer pairs for polymerase chain reaction (PCR) amplification of human parvovirus B19 DNA. F Virol Methods 1993;44: 155-65.

10 Kerr JR, Cartron JP, Curran MD, et al. A study of the role of parvovirus B19 in rheumatoid arthritis. Br f Rheumatol 1995;34:809-13. 